\title{
CORRELATION OF LEFT ATRIAL SIZE AND ATRIAL FIBRILLATION IN RHD WITH MITRAL VALVE DISEASE
}

\begin{abstract}
Raghavendra Mariyamballi1, Nalina Thimmappa², Pula Laxmi Bindumathi, Pooja Pillai ${ }^{4}$, Bhaskar Balasundaram 5
${ }^{1}$ Assistant Professor, Department of General Medicine, Sapthagiri Institute of Medical Sciences \& Research Centre, Bangalore. ${ }^{2}$ Associate Professor, Department of General Medicine, Sapthagiri Institute of Medical Sciences \& Research Centre, Bangalore. 3 Professor \& HOD, Department of General Medicine, Sapthagiri Institute of Medical Sciences \& Research Centre, Bangalore. ${ }^{4}$ Assistant Professor, Department of General Medicine, Sapthagiri Institute of Medical Sciences \& Research Centre, Bangalore. ${ }^{5}$ Assistant Professor, Department of General Medicine, Sapthagiri Institute of Medical Sciences \& Research Centre, Bangalore.
\end{abstract}

\section{ABSTRACT}

\section{BACKGROUND}

Atrial fibrillation $(\mathrm{AF})$, the most common sustained cardiac rhythm disturbance, commonly occurs with rheumatic heart disease, particularly mitral stenosis. Hemodynamic impairment and thromboembolic events result in significant morbidity\& mortality. Left atrial (LA) enlargement is one of the elements that evolve in the natural history of mitral stenosis. The objective of this study is to study the relation between echo cardio graphically determined left atrial size and atrial fibrillation in mitral valve disease (MVD).

\section{METHODOLOGY}

50 Patients with rheumatic heart disease with mitral valve disease were studied using ECG and ECHO, excluding patients with congenital heart diseases, non-rheumatic mitral valve disease, essential hypertension, patients undergone PTMC or valvuloplasty or valve replacement, coronary artery diseases, patients on antiarrhythmic drugs, pregnant women. Left atrial dimensions measured by ECHO in patients of MVD and AF on ECG were compared with the left atrial dimension of patients in sinus rhythm.

\section{RESULTS}

In this study 42 patients had left atrial size $>40 \mathrm{~mm}, 29(93.55 \%)$ of them were in atrial fibrillation and only 13(68.42\%) were in sinus rhythm. Among 8 patients with left atrial size $<40 \mathrm{~mm}, 2(6.45 \%)$ were in atrial fibrillation and $06(31.58 \%)$ were in sinus rhythm with $\mathrm{p}<0.02$ which is significant.

\section{CONCLUSION}

Atrial fibrillation incidence was common when left atrial dimension was above $40 \mathrm{~mm}$. There is a quantitative relation between left atrial size measured echocardiographically and the presence or absence of atrial fibrillation. These results may have therapeutic implication in that it may be possible with echocardiography, to identify patients in sinus rhythm, who are at high risk of developing atrial fibrillation. Prophylactic anticoagulation, antiarrhythmic therapy or both might be considered in management to prevent embolism.

\section{KEYWORDS}

Left Atrial Size; Atrial Fibrillation; Mitral Valve Disease.

HOW TO CITE THIS ARTICLE: Mariyamballi R, Thimmappa N, Bindumathi PL, et al. Correlation of left atrial size and atrial fibrillation in RHD with mitral valve disease. J. Evolution Med. Dent. Sci. 2016;5(19):978-981, DOI: 10.14260/jemds/2016/226

\section{INTRODUCTION}

Atrial fibrillation is a common arrhythmia that is found in 1 percent of persons older than 60 years to more than 5 percent of patients older than 69 years. In one study of men and women 65 years or older. A history of the congestive heart failure, valvular heart disease and stroke, left atrial enlargement, abnormal mitral or aortic valve function, treated systemic hypertension and advanced age was independently associated with prevalence of atrial fibrillation. Atrial fibrillation, whether it is persistent or intermittent, is a predictor of stroke.

Symptoms as a result of atrial fibrillation are determined by multiple factors, including the underlying cardiac status,

Financial or Other, Competing Interest: None.

Submission 21-01-2016, Peer Review 17-02-2016,

Acceptance 22-02-2016, Published 07-03-2016.

Corresponding Author:

Nalina Thimmappa,

Doctors Quarters, \#6, Sapthagiri Hospital,

Hesaragatta Road, Chikkabanavara,

Bangalore-560090.

E-mail: nalina2000@gmail.com

DOI: $10.14260 /$ jemds $/ 2016 / 226$ the rapid ventricular rate, and loss of atrial contraction. ${ }^{1}$

Atrial fibrillation commonly occurs with rheumatic heart disease, particularly mitral stenosis. It also occurs with many other cardiac disorders, including coronary artery diseases, congestive/hypertrophic cardiomyopathy, mitral valve prolapse and mitral valve annular calcification. ${ }^{2}$ In large surgical series, atrial fibrillation has been found in $40 \%$ cases with mitral stenosis and $25 \%$ of cases with mitral regurgitation. ${ }^{3}$ Left atrial enlargement is one of the elements that evolve in the natural history of mitral stenosis. Most investigators attribute left atrial enlargement to change in the left atrial pressure consequent to valvular obstruction and consider atrial fibrillation to be secondary phenomenon. 4,5,6

The Mechanical obstruction to flow across the mitral valve results in increased left atrial pressure with a rise in left atrial tension and myocardial oxygen consumption and the enlargement of the atrium is a manifestation of its failure. The increase in wall tension, combined with myocardial cellular disarray may result in electrophysiological changes and conduction properties and the perpetuation of atrial fibrillation.7,8,9,10 
These associations are important not only in understanding of the pathophysiology of atrial fibrillation, but also have potentially important clinical and therapeutic implications. Therefor if a subgroup of patients in normal sinus rhythm would be identified who are at risk of developing atrial fibrillation prophylactic anticoagulation and antiarrhythmic drugs might be used as a possible means of preventing atrial fibrillation induced emboli.

Echocardiography has proven to be a valuable noninvasive tool for quantitatively assessing left atrial size.11,12

The Present study is an attempt to assess the correlation between left atrial size and atrial fibrillation in mitral valve disease.

\section{MATERIALS AND METHODS}

The present study was conducted at tertiary hospital north Karnataka.

\section{METHOD OF COLLECTION OF DATA}

Information was collected through prepared proforma for each patient.

- All Patients were interviewed as per the proforma and a complete clinical examination was done.

- $\quad$ Cases of RHD with mitral valve disease diagnosed with clinical history, examination and $2 \mathrm{D}$ echocardiography.

- Patients were evaluated by ECG \& 2D Echo.

- Results were analyzed with appropriate statistical methods.

\section{Inclusion Criteria}

50 patients with clinical history \& examination suggestive of Rheumatic heart disease with mitral valve disease were taken for study. Detailed history was taken and clinical examination was carried out as per proforma.

\section{Exclusion Criteria}

- Congenital heart diseases

- Non Rheumatic mitral valve disease

- Essential hypertension

- Patients already having undergone PTMC or Valvuloplasty or valve replacement

- Coronary artery diseases

- Patients on antiarrhythmic drugs

- Pregnant women

Left atrial dimensions measured by ECHO in patients of MVD with AF on ECG were compared with the left atrial dimension of patients in sinus rhythm. All Patients underwent routine blood and urine examination, a chest X ray, ECG and ECHO Examination.

LA size was measured at end systole as a maximum distance between the anterior margin of posterior aortic root and the anterior margin of a posterior wall of LA at the aortic valve level. LA enlargement is considered to be present in left atrial dimension measured was more than or equal to $40 \mathrm{~mm}$. MV area was obtained by plannimetry.

\section{ECG}

A standard 12 lead ECG was recorded in all patients and was analyzed for evidence of AF. AF was said to be present if ECG shows irregular or undulating baseline, absent P-waves, presence me fibrillatory ' $f$ ' waves and varying $R \mathrm{R}$ interval. For those in sinus rhythm, ECG was analyzed for evidence of LA enlargement, such as P-wave width was $>0.11 \mathrm{Sec}$; Morris index was $>0.04 \mathrm{~mm}$ sec and Macruz index was $>1.66 \mathrm{~mm} / \mathrm{sec}$.

\section{RESULTS}

\section{Correlation Between Age and Patients Rhythm}

To correlate age of the patients with the patient's rhythm, patients were divided in to 2 groups, below 30 years and more than 30 years.

\begin{tabular}{|c|c|c|c|c|}
\hline AGE & $\begin{array}{c}\text { Cases with } \\
\text { sinus } \\
\text { rhythm }\end{array}$ & $\begin{array}{c}\text { Cases } \\
\text { with AF }\end{array}$ & Total & Percentage \\
\hline $\begin{array}{c}<30 \\
\text { Years }\end{array}$ & 11 & 11 & 22 & $50.00 \%$ \\
\hline $\begin{array}{c}>30 \\
\text { Years }\end{array}$ & 08 & 20 & 28 & $71.43 \%$ \\
\hline \multicolumn{7}{|l|}{ Table 1: Correlation Between Age and Patients Rhythm } \\
\hline
\end{tabular}

In present study, 20 cases $(71.43 \%)$ of more than 30 years had atrial fibrillation, while 11 cases (50.00\%), less than 30 years had atrial fibrillation.

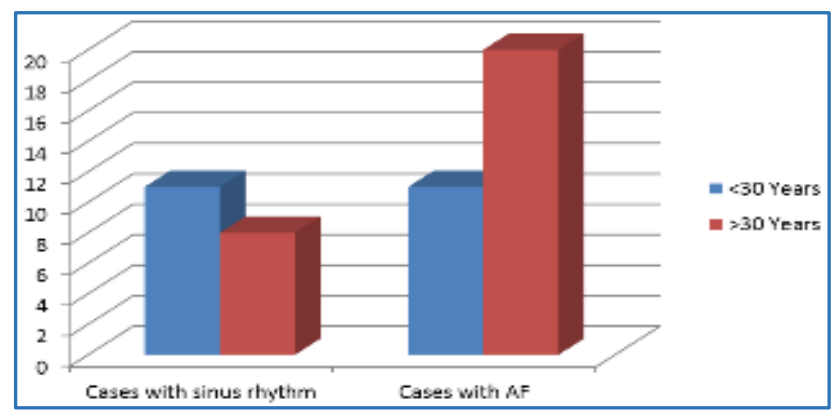

Chart-1: Showing Correlation Between Age and Patients Rhythm

\section{NATURE OF VALVULAR HEART DISEASE}

Showing the nature of the lesions in the 50 cases of Rheumatic mitral valve disease studied.

\begin{tabular}{|c|c|c|}
\hline Valvular lesions & No. of Cases & Percentage \\
\hline MS & 22 & $44 \%$ \\
\hline MR & 04 & $8 \%$ \\
\hline MS+MR & 24 & $48 \%$ \\
\hline Total & 50 & $100 \%$ \\
\hline \multicolumn{3}{|c|}{$\begin{array}{c}\text { Table 2: Shows the Nature of Lesions in the } 50 \text { Cases of } \\
\text { Rheumatic Mitral Valve Disease studied. }\end{array}$} \\
\hline
\end{tabular}

In the present study, isolated MS was observed in 22 cases (44\%), isolated MR was found in 4 cases, while combined MS and MR was found in 24 cases(48\%).

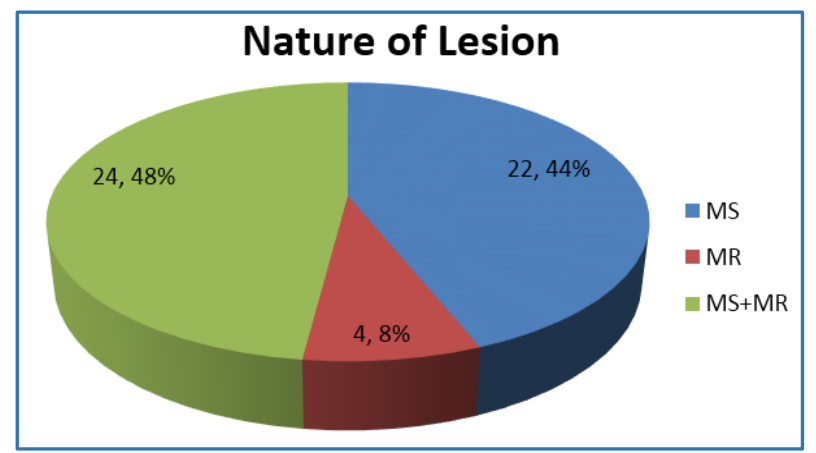

Chart-2: Showing the Nature of Lesions in the Study Group 
ECHO FOR LA ENLARGEMENT

Table - 3 shows LA dimensions obtained by M mode ECHO in the 50 cases studied.

\begin{tabular}{|c|c|c|c|}
\hline $\begin{array}{c}\text { LA } \\
\text { size(mm) }\end{array}$ & $\begin{array}{c}\text { Total } \\
\text { cases }\end{array}$ & $\begin{array}{c}\text { No. of cases } \\
\text { with sinus } \\
\text { rhythm }\end{array}$ & $\begin{array}{c}\text { No. of cases with } \\
\text { atrial fibrillation }\end{array}$ \\
\hline $21-30$ & 0 & 0 & 0 \\
\hline $31-40$ & 8 & 7 & 1 \\
\hline $41-50$ & 27 & 11 & 16 \\
\hline $51-60$ & 12 & 1 & 11 \\
\hline $61-70$ & 2 & 0 & 2 \\
\hline $71-80$ & 1 & 0 & 1 \\
\hline Total & 50 & 19 & 31 \\
\hline \multicolumn{4}{|c|}{ Table 3: Showing LA Dimensions on M Mode } \\
ECHO in the 50 Cases Studied \\
\hline
\end{tabular}

\begin{tabular}{|c|c|c|c|c|}
\hline Dimension & $\begin{array}{c}\text { No. of } \\
\text { case with } \\
\text { sinus } \\
\text { rhythm }\end{array}$ & $\begin{array}{c}\text { No. of } \\
\text { cases with } \\
\text { atrial } \\
\text { fibrillation }\end{array}$ & Total & $\begin{array}{c}\text { Percent- } \\
\text { age }\end{array}$ \\
\hline$<40 \mathrm{~mm}$ & $\begin{array}{c}06 \\
(31.58 \%)\end{array}$ & $\begin{array}{c}2 \\
(6.45 \%)\end{array}$ & 08 & $16 \%$ \\
\hline$>40 \mathrm{~mm}$ & $\begin{array}{c}13 \\
(68.42 \%)\end{array}$ & $\begin{array}{c}29 \\
(93.55 \%)\end{array}$ & 42 & $84 \%$ \\
\hline Total & $\begin{array}{c}\mathbf{1 9} \\
(\mathbf{3 8 . 0} \%)\end{array}$ & $\begin{array}{c}\mathbf{3 1} \\
\mathbf{( 6 2 \% )}\end{array}$ & $\mathbf{5 0}$ & $\mathbf{1 0 0 \%}$ \\
\hline
\end{tabular}

Table 4: showing analysis of Left Atrial dimension on $M$ Mode ECHO in the 50 Cases studied

$\left(\mathrm{X}^{2} \mathrm{yc}=5.53 . \mathrm{DF}=1, \mathrm{p}<0.02\right.$ significant $)$

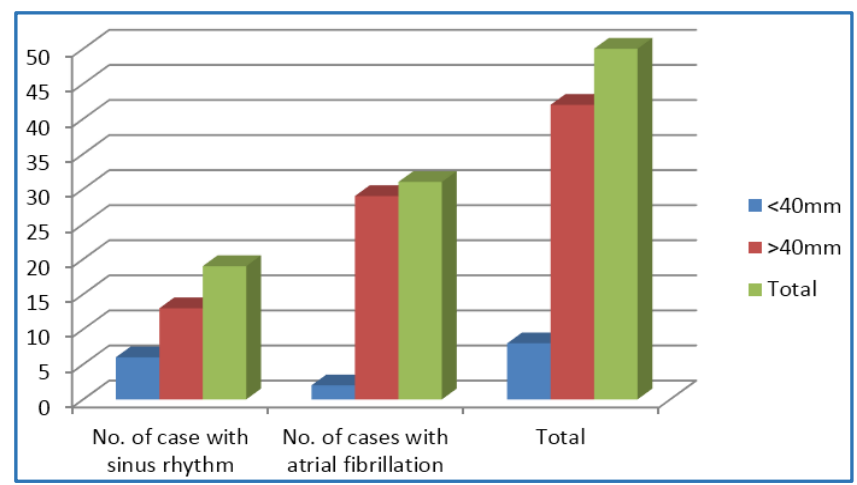

Chart - 3: Showing Analysis of Left Atrial Dimension on M- mode echo in Study Group

\section{DISCUSSION}

The present study comprised of 50 cases of Rheumatic mitral valve disease admitted at tertiary hospital in north Karnataka. The age of the patients in the present study ranged from 18 years to 75 years with a mean of 46.5 years. There were 12 males and 38 females, M: F ratio being 1.3:16 showing female preponderance.

\begin{tabular}{|c|c|c|}
\hline Study & Age Group & Incidence of AF \\
\hline Henry WL et al. ${ }^{12}$ & $>40$ years & $89.0 \%$ \\
\hline Jacob Jose et al. ${ }^{13}$ & $>30$ years & $79.0 \%$ \\
\hline Present Study & $>30$ years & $71.4 \%$ \\
\hline \multicolumn{2}{|c|}{ Age and Incidence of Atrial Fibrillation } \\
\hline
\end{tabular}

Increasing age i.e. increasing duration of the disease process is an important factor in the development of Atrial Fibrillation associated with mitral valve disease.

\section{Left Atrial Size}

In the present study LA size varied from $35 \mathrm{~mm}$ to $75 \mathrm{~mm}$ with a mean LA size of $53 \mathrm{~mm}$. out of 19 patients in sinus rhythm, LA size varied from $35 \mathrm{~mm}$ to $52 \mathrm{~mm}$ with a mean of $43.5 \mathrm{~mm}$. Out of 31 patients with the Atrial Fibrillation, LA size varied from $37 \mathrm{~mm}$ to $71 \mathrm{~mm}$ with the mean of $54 \mathrm{~mm}$. The difference observed in the mean LA size in patients with Sinus rhythm and Atrial Fibrillation was statistically significant $(\mathrm{P}<0.005)$.

Showing relationship of LA size and Atrial Fibrillation as observed in different studies.

\begin{tabular}{|c|c|c|}
\hline $\begin{array}{c}\text { Sl. } \\
\text { No. }\end{array}$ & Study & Conclusion \\
\hline 1 & $\begin{array}{c}\text { Henry WL et } \\
\text { al 12 }\end{array}$ & $\begin{array}{c}54 \% \text { patients had AF, when LA } \\
\text { size was }>40 \text { mm }\end{array}$ \\
\hline 2 & $\begin{array}{c}\text { Gad Keran et } \\
\text { al 14 }\end{array}$ & $\begin{array}{c}\text { LA size was larger }(37.6+/-10.8 \\
\text { mm) in patients with the ms. }\end{array}$ \\
\hline 3 & $\begin{array}{c}\text { Gupta V et } \\
\text { al 15 }\end{array}$ & $\begin{array}{c}90.7 \% \text { patients having AF had LA } \\
\text { size more than 50 mm }\end{array}$ \\
\hline 4 & $\begin{array}{c}\text { Mrozowska et } \\
\text { al 16 }\end{array}$ & $\begin{array}{c}\text { AF was rare when LA dimension } \\
\text { was }<40 \text { mm. }\end{array}$ \\
\hline 5 & $\begin{array}{c}\text { G. Singh et } \\
\text { al 17 }\end{array}$ & $\begin{array}{c}\text { Patients with RHD with a AF had } \\
\text { mean LA size of 50.2 mm. }\end{array}$ \\
\hline 7 & $\begin{array}{c}\text { Kulkarni AG } \\
\text { et al 18 }\end{array}$ & $\begin{array}{c}97.14 \% \text { of the patients with a AF } \\
\text { had LA size }>40 \text { with a average of } \\
55.6 \text { mm. }\end{array}$ \\
\hline Present Study & $\begin{array}{c}93.5 \% \text { patients with a AF had LA } \\
\text { size }>40 \text { mm with average of 53 } \\
\text { mm. }\end{array}$ \\
\hline
\end{tabular}

The results of the present study are comparable to studies mentioned above. The incidence of AF is more common when the Left Atrial size exceeds $40 \mathrm{~mm}$.

\section{SUMMARY}

- The Present study was undertaken at KIMS, Hubli composed of 50 cases of Rheumatic mitral valve disease admitted during 1st November 2007 and 31st October 2008.

- The age of Patients ranged from 18-75 years with a mean of 46.5 years, M: F ration being 1:3.

- 20 Cases of $>30$ years of age had AF, compared to 11 cases of $<30$ years of age.

- The ECHO study of LA Size of 50 patients revealed it to vary from $35 \mathrm{~mm}$ to $71 \mathrm{~mm}$ with a mean LA size of 53 mm.

- The LA size in 19 patients with sinus rhythm varied from $35 \mathrm{~mm}$ to $52 \mathrm{~mm}$ with a mean of $43.5 \mathrm{~mm}$.

- The LA size in 31 patients with atrial fibrillation varied from $37 \mathrm{~mm}$ to $71 \mathrm{~mm}$ with a higher mean of $54 \mathrm{~mm}$.

\section{CONCLUSIONS}

- Left atrial size is an important factor in the development of atrial fibrillation, in patients with rheumatic mitral valvular disease.

- Atrial fibrillation incidence was rare when left atrial dimension was below $40 \mathrm{~mm}$. 
- There is a quantitative relation between left atrial size measured echo cardio graphically and the presence or absence of atrial fibrillation.

These results may have therapeutic implication in that it may be possible with echocardiography, to identify patients in sinus rhythm, who are at high risk of developing atrial fibrillation. Prophylactic anticoagulation, antiarrhythmic therapy or both might be considered in the management to prevent embolism. Only a prospective study can determine whether the benefit of prophylactic therapy will outweigh the potential hazards of atrial fibrillation.

\section{REFERENCES}

1. Jeffrey E Olgin, Douglas P Zipes. Specific arrhythmias: Diagnosis and treatment, Braunwald's heart disease: a textbook of cardiovascular medicine, W.B. Saunders Company. Chapter 35, 2008; $8^{\text {th }}$ Edition:863-931.

2. Prystowsky EN, Benson DW, Fuster V, et al. Management of patients with AF. Circulation 1996;93:1262-77.

3. Gosselink AT, Crijins HSJ, Harmer HP, et al. Changes in left and right atrial size after cardioversion of atrial fibrillation: role of mitral valve disease. Am coll cardiol 1993;22(6):1666-72.

4. Mehta D, Ghosh J. Management of atrial fibrillation with reference to valvular heart disease. Indian Heart J 2002;54:312-320.

5. Diker E, Aydogdu S, Ozdemir M, et al. Prevalence and predictors of atrial fibrillation is rheumatic valvular heart disease. Am J Cardiol 1996;77:96-98.

6. Bailey GWH, Braniff BA, Hancock EW, et al. Relation of left atrial pathology to atrial fibrillation in mitral valvular disease. Ann Intern Med 1968;69:13-20.

7. Davies MJ, Pomerance A. Pathology of atrial fibrillation in man. Br Heart J 1972;34:520-5.
8. Probst P, Goldschlanger N, Selzer A. Left atrial size and atrial fibrillation in mitral stenosis. Factors influencing their relationship. Circulation 1973;48:1282-1287.

9. Adildskov JA, Miller K, Burgers MJ. Atrial fibrillation. Am j Cardiol 1971;28:263.

10. Catherine M. Otta and Robert O. Bonow. Valvular heart disease, braunwald's heart disease: a textbook of Cardiovascular medicine, W.B. Saunders company. Chapter 62, 2008; $8^{\text {th }}$ edition:1625-1712.

11. Selzer A. Atrial fibrillation revisited. N Engl Med 1982;306:1004-45.

12. Henry WL, Morgantroth J, Pearlman AS, et al. Relation between echo cardio graphically determined left atrial size and atrial fibrillation. Circulation 1976;53:273-9.

13. Duran NE, Durran I, Sonmez K, et al. Frequency and predictors of atrial fibrillation in severe mitral regurgitation. Anadolu Kardiyol Derg 2003;3(2):129-34.

14. Gad Keren, Tahel Etzion, Jack Sherez, et al. Atrial fibrillation and atrial enlargement in patients with mitral stenosis. Am Heart J 1987;114:1146-1155.

15. Gupta V, Agarwal S, Mohrotra A, et al. Left atrial enlargement as a predictor of atrial fibrillation in rheumatic mitral valve disease. JAPI 1996;44:903.

16. Mrozowska E, Rogowski W, Musial WJ, et al. Atrial fibrillation in mitral valve disease-risk factors. Pol Arch Med Wewn 1999;1010(1):45-53.

17. Singh G, Arora P. Study of left atrial size in atrial fibrillation. JAPI 2002;50:50.

18. Kulkarni AG, Mulay DV, Jilla P. A study of relation between left atrial size and atrial fibrillation. JAPI 2002;50:155. 